\title{
La marcación etimológica de los préstamos (exotismos y cultismos transmitidos por el inglés) en la lexicografía española
}

\author{
Juan Gómez Capuz \\ Universitat de València. \\ Grupo Val. Es. Co
}

\section{INTRODUCCIÓN: OBJETO DE ESTUDIO}

Una de las principales lagunas de la lexicografía española es la relativa a la información etimológica y diacrónica de las palabras de origen extranjero, sean extranjerismos recientes o préstamos antiguos y asimilados. En este sentido, nuestro trabajo se propone analizar dos casos particulares en los que la lexicografía española presenta graves deficiencias: la marcación etimológica ${ }^{1}$ de los exotismos transmitidos por el inglés (y secundariamente, por el francés) y de los neologismos técnicos de cuño grecolatino (tanto voces existentes en latín clásico como formaciones neológicas del lenguaje técnico-científico contemporáneo). Hemos escogido estos dos problemas porque afectan a un número elevado de entradas léxicas, pero también podríamos haber analizado otros sectores minoritarios todavía más marginados en la marcación etimológica de los diccionarios hispánicos, como las voces de lenguas periféricas europeas transmitidas por el inglés y el francés (gaélico CLAN, islandés GEYSER, flamenco KERMESSE, germánico o escandinavo ICEBERG, checo ROBOT, noruego SLALOM) y los falsos anglicismos acuñados en francés mediante formantes ingleses que han llegado a ser productivos en nuestra lengua vecina (AUTOSTOP, PRESSING, RECORDMAN, SMOKING, FOOTING, CARTER). Ahora bien, para no alargar en exceso este trabajo, nos hemos ceñido a los dos primeros casos en virtud del factor cuantitativo indicado antes.

Nuestro propósito será, pues, revisar los criterios de identificación y

${ }^{1}$ Implícita en la definición o explícita en algún lugar de la microestructura. 
marcación etimológica de los préstamos a la luz de los avances realizados en dominios conexos como la lingüística histórica, el estudio sobre los contactos interlingüísticos y la lexicografía moderna. En estos ámbitos, dedicaremos especial atención a las propuestas de renovación metodológica que se han producido en la filología hispánica (Chris Pratt, Emilio Lorenzo y Félix Rodríguez González) así como a la teoría y práctica lexicográficas desarolladas en otros países de lengua románica que se enfrentan con similares problemas (Francia e Italia).

\section{PRoblemas DE MÉTOdo}

Hemos apuntado la necesidad de examinar los avances realizados en la lingüística histórica y el estudio sobre los contactos interlingüísticos, ya que la marcación etimológica de los préstamos en lexicografía es inseparable de los problemas que suscita la propia identificación y detección del préstamo en los estudios sobre intercambios lingüísticos y contacto de lenguas; más aún, los criterios de identificación del préstamo en esta disciplina constituyen la base que en la necesariamente se apoyará la labor lexicográfica posterior.

En el estudio de los contactos interlingüísticos, las principales corrientes de opinión son las siguientes:

1. En los estudios tradicionales sobre los contactos de lenguas en el ámbito europeo predominan los criterios diacrónicos y formales: por un lado, la fonética histórica; por otro, la "historia misma de la palabra", entendida en la práctica como un criterio extralingüístico, de tipo onomasiológico, histórico y cultural.

2. Como reacción a los excesos historicistas, culturales, propios de la lingüística externa, la diversas corrientes estructuralistas defienden la aplicación de criterios sincrónicos y formales: los extranjerismos se conciben como un tipo léxico que destaca en un determinado estadio de lengua (sincronía) por sus rasgos formales anómalos (fonética, grafía, morfología).

3. El descriptivista norteamericano E. Haugen (1950, pp. 226-230) y los romanistas B. E. Vidos y T. E. Hope postulan la aplicación de un método integrado con diversos criterios complementarios en la identificación y detección del préstamo: formal (grafía y sonido), morfológico, semántico, diacrónico y extralingüístico. En función del criterio extralingüístico ("étymologie organique" en Vidos, "extralinguistic factors" en Hope), es legítimo suponer que un determinado préstamo técnico pro- 
venga de la lengua extranjera dominante en dicha área técnica.

En la filología hispánica, Chris Pratt (1980, pp. 59-89) propone aplicar los criterios extralingüísticos "en vez de de los propiamente lingüísticos cuando éstos resultan deficientes". De la aplicación de estos criterios, Pratt (1980, p. 81) concluye que los neologismos y exotismos presentes en español proceden casi siempre de lenguas intermediarias, en especial, francés (hasta 1950) e inglés (desde 1950 hasta hoy). Pratt (1980, 1986 y 1992) formaliza este polémico axioma mediante la dicotomía étimo inmediato/étimo último, la cual ha encontrado buena aceptación entre los estudiosos hispánicos, a la vez que presenta evidentes analogías con los criterios etimológicos aplicados por la lexicografía francesa o italiana. Según el hispanista inglés, los préstamos se deben atribuir a la lengua de étimo inmediato, es decir, la lengua intermediaria de la que proviene de manera directa e inmediata un determinado préstamo (detectable en función de criterios como las fechas de primera documentación en las lenguas intermediarias y el predominio relativo de éstas en el área temática a que pertenece el préstamo). La lengua de étimo último, por su parte, es la lengua de la que proviene en última instancia dicho préstamo (con frecuencia, latín, griego, lenguas europeas marginales y lenguas exóticas) y sólo es relevante en los estudios diacrónicos y en la erudición etimológi$\mathrm{ca}^{2}$. En la práctica, este criterio se traduce en la asignación de numerosos préstamos de apariencia grecolatina y exótica a las lenguas intermediarias o acuñadoras que los han transmitido al español: el francés y el inglés.

Aunque el papel del francés y del inglés como lenguas intermediarias de exotismos y voces de lenguas europeas periféricas y como lenguas

2 Sin embargo, el término étimo último en Pratt resulta excesivo o presuntuoso, ya que en muchas ocasiones podemos remontarnos a lenguas anteriores, incluyendo el hipotético étimo indoeuropeo. Así, el anglicismo clan deriva del gaélico clann, pero a su vez este procede del latín planta, como indica RANDO; por otra parte, al registrar el étimo último de exotismos procedentes de la India, algunas fuentes dan como "étimo último" una forma moderna hindi (p.ej. PANCH en ponche) y otras la forma clásica del sánscrito (PANCHA 'cinco'). Por todo ello, sería deseable sustituir el término maximalista étimo último por otro que se adecuase mejor a la compleja realidad étimológica, como nos ha hecho ver la Dra. $\mathrm{M}^{\mathrm{a}}$.T. Echenique (comunicación personal); sin embargo, ante la dificultad de hallar un término preciso y válido para todos los casos (entre otras propuestas personales, podemos sugerir étimo exótico/clásico, étimo convencional, étimo secundario), hemos optado por seguir empleando étimo último, aunque con las reservas expuestas en esta nota. 
acuñadoras de neologismos grecolatinos ha sido reconocido por diversos estudiosos hispánicos y europeos ${ }^{3}$, Pratt lamenta que las fuentes lexicográficas españolas -en especial, DRAE- registren únicamente la lengua de étimo último en muchos de estos casos: este proceder ofrece la errónea impresión de que la lengua española ha mantenido contactos directos y regulares con culturas muy alejadas por un lado, $y$ ha acuñado numerosos neologismos grecolatinos propios del lenguaje científico, a pesar del atraso tecnológico de los países hispánicos, por otro.

Frente al nacionalismo hispánico de la Academia y frente al nacionalismo anglosajón de Pratt, Emilio Lorenzo y Félix Rodríguez González postulan nuevamente la necesidad de un enfoque integrado en la identificación del préstamo en general y del anglicismo en particular. Así lo expone F. Rodríguez González (1996, pp. 306-307), al presentar los criterios metodológicos que han guiado la redacción de su Nuevo Diccionario de Anglicismos :

\begin{abstract}
Apoyarse en criterios extralingüísticos únicamente, en efecto, es una operación arriesgada y poco recomendable para un diccionario de extranjerismos o de anglicismos, donde, al menos por razones prácticas, no debiera desatenderse del todo la forma característica de la lengua prestadora. De este modo, por ejemplo, incluimos curry (del tamil kari), cuya grafia apunta a la influencia inmediata del inglés. (...) una combinación de criterios, basados en la morfología y en la semántica del término en cuestión, así como en la especifidad cultural del concepto prestado, puede arrojar luz sobre el problema de su identificación e inserción lexicográfica.
\end{abstract}

No obstante, tanto F. Rodríguez como E. Lorenzo adoptan algunos de los aspectos positivos de la metodología de Ch. Pratt, en especial la dicotomía étimo último/étimo inmediato y la decisión de atribuir los préstamos a la lengua de étimo inmediato, "aunque sin la rigidez con que lo aplicado y defendido Chris Pratt repetidamente en sus estudios sobre el anglicismo" (F. Rodríguez, 1996, p. 306).

En este sentido, el académico Emilio Lorenzo ha manifestado en numerosos estudios parciales (Lorenzo 1971, 1980, 1995) y en su reciente obra de conjunto (Lorenzo 1996) una actitud cauta, mesurada y realis-

${ }^{3}$ Los cuales han propuesto criterios similares a la distinción entre étimo inmediato y étimo último. Es el caso de I. Klajn (1972, p. 16-18), REY-DEBOVE y GAGNON y RANDO entre los europeos y P. J. Marcos Pérez (1971, pp. 43-44), Contreras (1988, pp. 597-599) y R. Penny (1991, p. 230) entre los estudiosos de la filología hispánica. 
ta en la consideración como anglicismos de exotismos, voces europeas y neologismos grecolatinos presuntamente transmitidos o acuñados por la lengua inglesa:

1. Reconoce ampliamente el papel mediador del inglés en el tránsito de exotismos de diversa procedencia.

2. Es partidario de atribuir a determinadas lenguas modernas la acuñación de neologismos técnicos grecolatinos, siempre y cuando existan datos concretos (fecha, nombre y país del inventor) que así lo atestigüen 4 . Tal como hemos manifestado en la introducción, reiteramos que el propósito de este artículo es el de analizar los problemas de identificación y marcación etimológica que suscitan los préstamos en la lexicografía española. Tomando como base las propuestas de E. Lorenzo y F. Rodríguez González y algunos planteamientos de Ch. Pratt, examinaremos un corpus selecto de préstamos agrupados en los dos bloques que seleccionamos al comienzo del artículo en virtud de su mayor importancia numérica: exotismos y neologismos técnicos grecolatinos.

Los diccionarios seleccionados intentan cubrir los diversos problemas suscitados por estos elementos léxicos alógenos:

1. Diccionarios etimológicos, limitados al DCECH.

2. Diccionarios normativos: DRAE-1992, aunque con referencias esporádicas a ediciones anteriores (DRAE-1984).

3. Diccionarios de uso, donde alternan los clásicos (DUE) con los más recientes y actualizados (Vox y LAROUSSE).

4. Diccionarios de extranjerismos: Alfaro, Alzugaray, Hoyo y Doval. Aunque estos diccionarios son los más útiles para registrar el léxico seleccionado, presentan graves deficiencias metodológicas: en su inmensa mayoría, se trata de diccionarios compilados por lexicógrafos "aficionados" , los cuales desconocen los criterios básicos de la teoría y práctica lexicográfica $\mathrm{y}$, por supuesto, de la investigación etimológica.

5. Finalmente, también nos serviremos de los abundantes datos eti-

${ }^{4}$ Por lo que respecta a los dos grupos de palabras que presentan problemas en su marcación etimológica, pero que no analizaremos -por cuestiones de espacio- en este trabajo, consideramos conveniente indicar que Emilio Lorenzo también atribuye al inglés el papel mediador en el tránsito de préstamos procedentes de lenguas europeas periféricas o marginales (noruego, islandés, checo, etc.) y considera "galicismos anglificados" y "creaciones del francés con ropaje inglés" una serie de términos de apariencia inglesa que, en realidad, han sido acuñados en francés y posteriormente "exportados" al español (los falsos préstamos).

${ }^{5}$ Este es el término empleado -en el original inglés- por Y. Malkiel (1968). 
mológicos que aporta la reciente monografía de E. Lorenzo (1996), concebida casi a manera de diccionario, así como del testimonio de otros diccionarios de extranjerismos realizados en el ámbito románico, como REYDEBOVE y GAGNON y HöFLER para el francés, y RANDO para el italiano.

\section{EXOTISMOS TRANSMITIDOS POR MEDIACIÓN DEL INGLÉS (Y DEL FRANCÉS)}

El reconocimiento del papel mediador del francés y del inglés en el tránsito de exotismos al español es cada vez mayor en la lexicografía española, aunque todavía pervive en algunos diccionarios -en especial, DRAE y, por influjo directo, Vox- la costumbre de marcar sólo el étimo último, es decir, la lengua exótica de la que proviene en última instancia. El hecho de registrar en ocasiones el étimo último se explica en la práctica -aunque no se justifica metodológicamente- por el hecho de concebir estos préstamos como xenismos que designan realidades propias de culturas exóticas.

\subsection{Hindi, urdu, persa, sánscrito, indostánico, bengalí y tamil}

En este grupo, las referencias al inglés como lengua intermediaria o de étimo inmediato son frecuentes y constantes, quizá por la estrecha vinculación de la India con el Imperio Británico y por la forma exterior inglesa (criterio formal de identificación del préstamo) con que han llegado esos exotismos hasta el español:

1. En efecto, las formas que todavía se presentan en la lengua escrita con la grafía mediadora inglesa son asignadas sin excepción al inglés: bungalow 'casa playera' ( $<$ hindi BANGLA 'bengalí'); curry (tamil KARI 'salsa').

2. La asignación al inglés también es uniforme en los casos en los que la forma anglicada cede terreno ante la hispanización académica ${ }^{6}$ : khaki/caqui 'color pardo u ocre, típico de uniforme militar' (< urdu KHAKI o persa HAK, 'polvo, color de polvo'); punch/ponche 'bebida de cinco ingredientes' ( $<$ hindi PANCH y sánscrito PANCHA 'cinco'); shampoo/champú 'jabón para el cabello' ( $<$ hindi CHAMPO, imperativo de CHAMPNA 'apretar, frotar').

3. En el caso de pijama 'traje de dormir' $(<$ hindi o indostánico PAE-

${ }^{6}$ En las siguientes parejas de términos, el primero es la forma mediadora inglesa y el segundo la hispanización académica. 
JAMA 'vestido de pierna'), la existencia de la forma gráfica hispanoamericana piyamas (admitida en DRAE) revela el sonido palatal $/ \mathrm{d} \xi /(>/ \mathrm{y} /) \mathrm{de}$ la $<j>$ en la pronunciación inglesa y por tanto el papel mediador del inglés, reconocido por Drae, DCECH, Alfaro, Hoyo, Vox y LAROUSSE. Es también el caso de yute 'materia textil', procedente del bengalí JHUTO por mediación del inglés jute, como indican DCECH y LAROUSSE7, aunque DRAE sólo menciona el étimo inmediato inglés.

4. En algunos exotismos antiguos bien documentados, también predomina la asignación al inglés, aunque en algún caso DRAE opta por la lengua de étimo último: jungla procede del hindi JANGAL o del sánscrito JANGALA a través del inglés jungle, como reconocen DRAE, VOX y ALFARO; parchís también procede del hindi o indostánico PACISI/PACIS 'veinticinco' a través del inglés parcheesi, como reconocen Hoyo y Vox, pero en este caso DRAE remite directamente al indostánico.

5. Por último, los escasos préstamos de estas lenguas que conservan una forma clásica sánscrita y no evidencian rasgos formales anglicados son atribuidos a la lengua de étimo último, como ocurre con avatar (sánscrito) en Drae y Vox, aunque Hoyo y Doval reivindican el papel intermediario del inglés.

\subsection{Tibetano, malayo, chino, lenguas australianas y polinesias}

Se repiten, a grandes rasgos, las situaciones examinadas en el bloque anterior.

1. Los exotismos que presentan rasgos formales anglicados son atribuidos sin vacilación al inglés, hasta el punto de omitir la lengua oriental o de étimo último: para ketchup, HoYo reconstruye la cadena chino KE-SIAP 'salsa de pescado con vinagre' > malayo kechup > inglés ketchup/catchup/catsup, mientras que VOX y LAROUSSE se limitan a considerarlo "voz inglesa".

2. Los exotismos que presentan una forma anglicada y otra adaptada tienden a ser catalogados como anglicismos: gong/gongo 'instrumento de percusión, batintín' es considerado voz inglesa de origen malayo por Drae, Larousse, Hoyo, Doval y Alzugaray, mientras que Vox lo remite directamente al malayo y DCECH lo interpreta como formación onomatopéyica.

3. La importancia de estos criterios formales en la identificación del

7 También RANDo y REY-Debove y GaGNON para el italiano y el francés. 
préstamo se pone de manifiesto al observar ciertos casos en que se atribuye al francés el tránsito de exotismos pertenecientes a territorios de colonización inglesa: es el caso de la voz aborigen australiana CANGURO: pese a proceder de Australia, no es asignado al inglés o a la lengua aborigen correspondiente, sino que, en función de estos criterios formales (vocalismo), DrAE, DCECH y DUE señalan el francés como lengua intermediaria en su paso al español: en efecto, el español canguro sólo puede proceder de la forma francesa kangourou y en ningún caso de la inglesa kangaroo.

4. En alguna ocasión, se atribuye al inglés la transmisión de un exotismo y al francés la transmisión de otro exotismo de la misma familia léxica: en función de criterios lexicogenésicos, DCECH, DRAE, VoX y LAROUSSE sostienen que el español tatuar procede del polinesio TATÄU por intermedio del inglés to tattoo, pero el derivado tatuaje procede de la forma francesa tatouage (ya que en inglés el nombre postverbal equivalente es también tattoo, sin sufijo derivativo) ${ }^{8}$.

5. Cuando estos orientalismos presentan una apariencia externa exótica pero carecen de rasgos formales anglicados, se asignan normalmente a la lengua de étimo último, como ocurre con orangután, del malayo ORANG HUTAN 'hombre de los bosques')'. En cambio, polo 'deporte hípico' ( $<$ tibetano o balti POLO 'pelota'), pese a carecer de rasgos formales anglicados, es asignado al inglés por todos los diccionarios (DCECH, Drae, Vox, Larousse, Hoyo y Doval) en función de un criterio extralingüístico: la fama de este deporte en la alta sociedad inglesa.

\subsection{Esquimal y lenguas amerindias de América del Norte}

Los exotismos de este bloque siempre son asignados al inglés en calidad de lengua intermediaria, debido a la conocida colonización anglosajona de estas tierras y a la escasez de contactos directos con otros pueblos europeos (holandeses, portugueses, españoles, aunque cabría matizar que los franceses sí desempeñaron un importante papel en amplias zonas centrales de los actuales Estados Unidos y Canadá):

1. La atribución al inglés es evidente cuando el exotismo crudo pre-

8 Esta hipótesis también es defendida por E. Lorenzo (1996, p. 442). En cambio, para el italiano, RANDO atribuye a intermediario francés tanto tatuare como el derivado tatuaggio.

${ }^{9}$ En cambio, DCECH postula un intermediario francés, inglés u holandés. 
senta rasgos formales anglicados, aunque coexista con la adaptación española: igloo/iglú (< esquimal IDGLU[VIVAG] 'casa de nieve').

2. También se atribuyen al inglés préstamos con formas exóticas no necesariamente anglicadas (kayak 'canoa de piel de foca', del esquimal QAIAQ) o con formas ya hispanizadas, carentes de rasgos formales ingleses (mocasin 'calzado sin cordones', de origen algonquino a través del inglés moccasin).

\section{NEOLOGISMOS TÉCNICOS DE CUÑO GRECOLATINO}

Recordemos que Chris Pratt (1980, 1986 y 1992) defendía la asignación al inglés o francés de los neologismos técnicos de cuño grecolatino que habían sido acuñados y transmitidos al español por estas lenguas modernas.

En cambio, diversos estudiosos europeos e hispánicos ${ }^{10}$ son partidiarios de no incluir estos neologismos grecolatinos en las nóminas de galicismos y anglicismos (y de no reconocerlos como tales en los diccionarios), porque consideran que se trata de un patrimonio común de las lenguas occidentales de cultura.

Ante estas actitudes extremas opuestas, debemos destacar nuevamente la actitud cauta, mesurada y realista de E. Lorenzo (1971, 1980, 1995, 1996), especialmente clarificadora con relación a este polémico aspecto de la marcación etimológica:

a) E. Lorenzo es partidario de atribuir a determinadas lenguas modernas la acuñación de neologismos técnicos grecolatinos, siempre y cuando existan datos concretos que así lo atestigüen ${ }^{11}$. Estos datos concretos (fecha, nombre y país del inventor) suelen ser fáciles de obtener en el caso de inventos (p. ej. insulina, 1922) y marcas registradas (p. ej. vaselina, 1870).

b) En cambio, cuando se trata de genealogías "confusas o impenetrables, que se prestan a todo género de conjeturas", E. Lorenzo prefiere limitarse a indicar el étimo último: es el caso de televisión, telescopio, etc. En este sentido, el académico español reconoce que la tradición etimológica española, en la que siempre destacó un selecto grupo de latinistas y helenistas, solía esquivar prudentemente estas polémicas cues-

10 I. Klajn (1972, p. 14-15). H. Urrutia Cárdenas (1978, p. 261), M. C. Resnick (1981, p. 145) y G. Latorre Ceballos (1991, pp. 766-767) .

11 Esta postura escompartida por L. Contreras (1988, pp. 597-599). 
tiones de paternidad indicando el étimo último griego o latino o, simplemente, los componentes del neologismo (p. ej. televisión, de TELE y VISIÓN).

Aunque E. Lorenzo respeta en principio este proceder $^{12}$, critica la cautela académica en dos casos:

A) Cuando DRAE opta por el étimo último grecolatino de neologismos claramente identificados con la cultura moderna anglosajona:

1. Uno de los ejemplos aportados por E. Lorenzo (1995, pp. 168170) es el adjetivo psicodélico: en este caso, no nos hallamos ante un helenismo compuesto de PSICO- y DELOIN 'mostrar' -como indican DRAE y Vox-sino ante una adaptación del inglés psychedelic, voz inventada en 1956 y de gran vigencia entre los movimientos contraculturales anglosajones, como de hecho "reconocen los diccionarios franceses e italianos", apostilla E. Lorenzo ${ }^{13}$.

2. La familia léxica de detective, detectar y detector procede del inglés a través de vehículos diversos como el cine y las novelas en el primer caso y la técnica moderna en los dos restantes, aunque en última instancia todos ellos remontan al verbo latino detego. Aunque Alfaro, DCECH, Due, Hoyo y DrAe-1992 remiten en las tres palabras al inglés como lengua de étimo inmediato, DRAE-1984 incurría en una incoherencia etimológica, ya que derivaba detective/detectar del inglés y detector del sustantivo latino DETECTOR, -ORIS ${ }^{14}$.

B) Este último ejemplo nos lleva a la segunda deficiencia advertida por E. Lorenzo, a saber, cuando este afán clasicista desemboca en verdaderos fantasmas lexicográficos. Así, transistor es la amalgama o acrónimo acuñado en inglés norteamericano (en 1947, en los laboratorios de la Bell Telephone) a partir de los latinismos TRANSFER + RESISTOR, los cuales justifican el fundamento de este aparato (esta es la etimología propuesta por Hoyo, Doval, Drae-1992, así como ReY-Debove y GAGNON,

12 Muy distinto del que han seguido los diccionarios etimológicos europeos, incluidos los franceses e italianos (REY-DEBOVE y GAGNON, HöFLER y RANDO).

13 En efecto, la filiación moderna y anglosajona de este aparente helenismo también es defendida por los diccionarios franceses aún más precisos: es voz acuñada en inglés en 1956 por el psiquiatra canadiense H. Osmond.

14 Esta incoherencia del diccionario académico es advertida $-\mathrm{y}$, como vemos, enmendada en DRAE 1992- por E. Lorenzo (1996, p.183). Por su parte, REY-DEBove y GAGNON también derivan el sustantivo francés détecteur -al parecer, cultismo antiguo y autóctono- del latín DETECTOR, -ORIS, mientras que, en italiano, RANDO lo deriva de la formación culta y neológica inglesa detector, formada con el participio pasado DETECTUS más el sufijo agentivo -or. 
HÖFLER y RANDO). Sin embargo, DRAE-1984, en su afán por remontarse al presunto étimo último, llega a inventarse un sustantivo latino de la $3^{\mathrm{a}}$ declinación, TRANSISTOR, -ORIS, etimología "fantasmal" y "disparatada", que queda subsanada en DrAE-1992, como señala E. Lorenzo (1995, p. 169 y 1996, pp. 22 y 78).

Por otra parte, es obvio que la cautela académica también desemboca en decisiones metodológicas erróneas cuando sólo se consigna el étimo último grecolatino de los inventos y marcas comerciales de origen inglés.

1. Según E. Lorenzo (1996, pp. 263-264), keroseno/queroseno es un derivado del petróleo creado en Estados Unidos en 1854 y el nombre kerosene (del griego KERÓs 'cera' y el sufijo científico -ENE) se debe a su propio inventor. Además, la forma oral querosín, usual en la América hispana (registrada por ALFARO), delata la procedencia norteamericana (cfr.

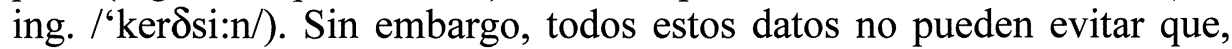
nuevamente, DRAE-1992 y Vox prefieran remontarse al étimo último griego.

2. Cyclostyle es el nombre de un invento (marca comercial según Hoyo) que presenta las formas hispanizadas ciclostil y ciclostilo. En este caso, DRAE y HoYo reconocen el papel mediador del inglés ${ }^{15}$, mientras que DuE y Vox se remontan a las raíces griegas KIKLOS y STYLOS.

3. Termo es el nombre comercial dado por su inventor inglés a un recipiente especial que mantiene calientes los líquidos (en inglés, Thermos o thermos bottle), como indican Hoyo, Lorenzo (1996, p. 445) y REY-DEBove y GAGNON. En cambio, otros diccionarios españoles adoptan una postura más ambigua o decididamente etimologista: DRAE lo cataloga como "nombre comercial registrado" pero no explicita en ningún momento la mediación inglesa; Vox, por su parte, va todavía más lejos y lo asigna directamente al griego THERMOS.

Un grupo especial de los neologismos grecolatinos está constituido por latinismos crudos cuya difusión en español parece estar motivada por usos jurídicos, comerciales o técnicos de origen anglosajón. En estos casos, la filiación latina del vocablo es indudable, pero el papel mediador del inglés resulta visible en alteraciones semánticas y categoriales, así como la referencia única a conceptos y objetos del mundo actual; por tanto, criterios semánticos, morfológicos y extralingüísticos favorecen la

15 E. Lorenzo (1996, p. 155) reconoce su intervención en la rectificación académica, en favor del papel intermediario del inglés. 
identificación de estos aparentes latinismos crudos como anglicismos:

1. La hegemonía comercial estadounidense y el criterio formal en la identificación del préstamo (aspecto fónico-gráfico de la palabra, con $s$ líquida y patrón acentual '... -or) son los factores responsables de la catalogación de sponsor 'patrocinador' como anglicismo por Vox, Alzugaray, Hoyo, Doval y LARousse, aunque en el fondo remonta al sustantivo latino SPONSOR, -ORIS 'fiador, garante'.

2. La no menos palpable hegemonía militar norteamericana es el criterio extralingüístico determinante en la consideración de misil/misil (< inglés MissiLE) 'proyectil autopropulsado' como anglicismo en Vox, Hoyo y Doval. En este caso, la actitud de DRAE resulta de nuevo incoherente, como denuncia E. Lorenzo (1996, p. 298): DRAE-1984 lo deriva del inglés missile, procedente este a su vez del latín MISSILIS; en cambio, DRAE-1992 consigna sólo el étimo último latino MISSILIS ${ }^{16}$.

3. CAMPus, en su acepción de 'conjunto de terrenos y edificios pertenecientes a la Universidad', es un anglicismo ampliamente difundido por el cine y la literatura norteamericana: así lo reconocen ALFARO, DRAE, Alzugaray, Hoyo y Doval (también Rey-Debove y Gagnon y HöFLER), mientras que Vox lo considera voz latina.

4. Alfaro y Hoyo matizan que el latinismo ITEM puede ser adverbio y sustantivo: como adverbio ('también', 'además'), es latinismo antiguo en español (con la forma item más, en el lenguaje jurídico); en cambio, como sustantivo, con los valores de 'punto', 'apartado', 'concepto', 'unidad', ha llegado al español por intermedio del inglés (como lo demuestra su frecuente empleo actual en lingüística, informática y tecnología de la información). DRAE registra todas estas acepciones (como adverbio y como sustantivo), pero las atribuye directamente al latín.

5. El empleo de los latinismos JUNIOR/SENIOR postpuestos a un apellido para diferenciar a un hijo de su padre es un uso, a todas luces, anglosajón: así lo reconocen Dcech, Alfaro, Vox, Hoyo y Doval. AlZugaraY y LAROUSSE, en cambio, lo consideran latinismo con este valor, mientras que DRAE lo cataloga como latinismo, aunque sólo con la acepción clásica de 'religioso joven'.

A la vista de estos ejemplos, y siguiendo la argumentación que subyace a los comentarios de E. Lorenzo, podemos concluir que la explicitación de la lengua intermediaria en la marcación etimológica del diccio-

16 Según algunos autores, como ReY-Debove y GAGNON, el étimo latino es el neutro MISSILE. 
nario es, en numerosas ocasiones, un lujo bastante arriesgado, pero en otros casos constituye una necesidad, pues de lo contrario el lector no podrá captar la especifidad técnica o cultural del vocablo en cuestión, como ocurre con psicodélico, detective, detector, transistor, ciclostil, sponsor, misil, campus y junior.

\section{CONCLUSIONES}

Aunque somos conscientes, con E. Lorenzo (1995, p. 171) y F. Rodríguez (1996, p. 308, n. 6), de que las disquisiciones y sutilezas etimológicas de muchos préstamos no pueden tener cabida, por razones de brevedad, en un diccionario monolingüe normal, los problemas analizados en este artículo ponen de manifiesto la carencia de criterios coherentes en la asignación etimológica y en la identificación de un mismo préstamo. Como consecuencia de esta alarmante carencia de métodos y de la pervivencia de los planteamientos clasicistas y academicistas, sigue siendo frecuente la atribución a lenguas europeas alejadas, lenguas exóticas y lenguas clásicas (griego y latín) de préstamos transmitidos al español por mediación del inglés ( $\mathrm{y}$ a veces del francés), papel mediador revelado por la aplicación de criterios formales, semánticos y extralingüísticos, y como de hecho reconocen la mayoría de los diccionarios europeos.

Por ello, sería deseable una revisión general de los métodos de investigación etimológica aplicados a la lexicografía española. Esta tarea pasa por dos frentes:

a) un alineamiento con los criterios etimológicos aplicados en las tradiciones lexicográficas francesa e italiana;

b) el aprovechamiento de los métodos empleados en la identificación del préstamo en los estudios sobre contactos interlingüísticos, donde defendemos un enfoque integrado que concilie los criterios formales, morfológicos, semánticos, diacrónicos y extralingüísticos, como los que han propuesto sucesivamente Haugen, Vidos, Hope, E. Lorenzo y F. Rodríguez González. 


\section{BIBLIOGRAFÍA}

\section{DiCCIONARIOS}

Alfaro: Alfaro, Ricardo J. (1970): Diccionario de anglicismos, Madrid, Gredos, $3^{\mathrm{a}}$ ed.

Alzugaray: Alzugaray, J. J. (1985): Diccionario de extranjerismos, Madrid, Dossat.

DCECh: Corominas, J. y J. A. Pascual (1981): Diccionario critico etimológico castellano e hispánico, Madrid, Gredos.

Doval: Doval, Gregorio (1996): Diccionario de expresiones extranjeras, Madrid, Ediciones del Prado.

DRAE-1984: ReAl ACADEMIa EsPaÑola (1984): Diccionario de la lengua española, Madrid, Espasa-Calpe, $20^{\mathrm{a}}$ ed.

DRAE-1992: ReAl ACADEMIA EsPañola (1992): Diccionario de la lengua española, Madrid, Espasa-Calpe, $21^{\mathrm{a}} \mathrm{ed}$.

HÖFLER: HÖFLER, Manfred (1982): Le Dictionnaire des anglicismes, París, Larousse.

Hoyo: Hoyo, Arturo del (1995) Diccionario de palabras y frases extranjeras, Madrid, Aguilar, $2^{\mathrm{a}}$ ed.

Larousse: LARousse (1996) Gran Diccionario de la Lengua Española, Barcelona, Larousse.

Due: Moliner, María (1966): Diccionario de uso del español, Madrid, Gredos.

RANDO: RANDO, Gaetano (1987): Dizionario degli anglicismi nell'italiano postunitario, Florencia, Olschki.

Rey-Debove y Gagnon: Rey-Debove, J. y G. Gagnon (1990): Dictionnaire des anglicismes, París, Robert, $3^{\mathrm{a}}$ ed.

Vox: Alvar EzQuerra, M. (dir.) (1990): Diccionario actual de la lengua española, Barcelona, Vox-Bibliograf.

\section{EsTUDIOS}

CONTRERAS, Lidia (1988): "Los anglicismos en el léxico del habla culta de Santiago de Chile", Actas del VI Congreso de la ALFAL (Phoenix, Arizona, septiembre de 1981), México, UNAM, pp. 593654.

DARDANO, Maurizio (1986): “The Influence of English in Italian", en W. 
Viereck y W. D. Bald (eds.), English in Contact with other Languages. Studies in honour of Broder Carstensen on the occasion of his $60^{\text {th }}$ birthday, Budapest, Akadémiai Kiadó, pp. 231-252.

GÓMEZ CAPUZ, Juan (1997): Anglicismos en español actual: su estudio en el registro coloquial, Valencia, Tesis Doctoral inédita.

AúgEN, Einar (1950): "The Analysis of Linguistic Borrowing", Language, 26, pp. 210-231.

HoPE, Thomas E. (1971): Lexical Borrowing in the Romance Languages: a critical Study of Italianisms in French and Gallicisms in Italian from 1100 to 1900, Oxford, Basil Blackwell.

KLAJN, Ivan (1972): Influssi inglesi nella lingua italiana, Florencia, Olschki.

Latorre Ceballos, Guillermo (1991): "Anglicismos en retirada: contacto, acomodación e intervención en un sistema léxico", en César Hernández et al (eds.),"El español de América". Actas del III Congreso Internacional de El Español de América, vol. II, Valladolid, Junta de Castilla y León, pp. 765-773.

LoREnzo, Emilio (1995): "Anglicismos", en M. Seco y G. Salvador (coords.), La lengua española, hoy, Madrid, Fundación Juan March, pp. 165-174.

LORENZO, Emilio (1996): Anglicismos hispánicos, Madrid, Gredos.

MALKIEL, Yakov (1968): "Hispanic Philology", en T. A. Sebeok (ed.), Current Trends in Linguistics, Volume 4: Iberoamerican and Caribbean Linguistics, La Haya, Mouton, pp. 158-228.

MARCOS PÉreZ, Pedro Jesús (1971): Los anglicismos en el ámbito periodístico (algunos de los problemas que plantean), Valladolid, Universidad.

PENNY, Ralph (1991): A History of the Spanish Language, Cambridge, CUP.

PRATT, Chris (1980): El anglicismo en el español peninsular contemporáneo, Madrid, Gredos.

PraTt, Chris (1986): "Anglicisms in Contemporary European Spanish", en W. Viereck y W. D. Bald (eds.), English in Contact with other Languages. Studies in honour of Broder Carstensen on the occasion of his 60 th birthday, Budapest, Akadémiai Kiadó, pp. 345-367.

PRATT, Chris (1992): "The status of Loan-words in modern monolingual dictionaries", en Actas del IV Congreso de "Euralex" (Benalmádena 1990), Barcelona, VOX-Bibliograf, pp. 509-516.

RESNICK, Melvyn C. (1981): Introducción a la historia de la lengua española, Washington D. C., Georgetown University Press. 
RoDRíGUEZ GonZÁLEZ, Félix (1996): "Lexicografía de los anglicismos en español contemporáneo. A propósito del Nuevo Diccionario de Anglicismos", en C. Schmitt y W. Schweickard (eds.), Kulturen im Dialog: die Iberoromanischen Sprachen aus interkultureller Sicht. Akten der gleichnamigen Sektion des Bonner Hispanistentages (2.4.-3. 1995), Bonn, Romanistischer Verlag, pp. 300-314.

URRUTIA CÁRDENAS, Hernán (1978): Lengua y discurso en la creación léxica, Editorial Planeta/Universidad de Deusto.

VIDos, B. E. (1965): Prestito, espanzione, migrazione dei termini tecnici nelle lingue romanze e non romanze. Problemi, metodo e resultati, Florencia, pp. 355-378. 